\title{
Interactive comment on "BESS-STAIR: a framework to estimate daily, 30-meter, and allweather crop evapotranspiration using multi-source satellite data for the U.S. Corn Belt" by C. Jiang et al.
}

\author{
C. Jiang et al.
}

chongya.jiang@gmail.com

Received and published: 4 December 2019

1. The study "BESS-STAIR: a framework to estimate daily, 30-meter, and all-weather crop evapotranspiration using multi-source satellite data for the U.S. Corn Belt" used the BESS model with $30-\mathrm{m}$ fused inputs from a automated data fusion algorithm (STAIR) to simulate fine resolution cropland ET across the U.S. Corn Belt from 2000 to 2017. The results showed good performance compared with field measurement, indicating that BESS-STAIR is applicable for field scale ET simulations in the U.S. Corn Belt, which is useful and meaningful for agricultural water management and precision 
agriculture applications. The manuscript was well written and followed a good logic. Lots of work was done by the authors to explore applicable and reliable methods for agricultural management. It is good for the farmers and decision makers to know agricultural water demands. Thus, I think this study could be considered for publication in this journal.

$\rightarrow$ Dear reviewer: we greatly appreciate your positive summary on our manuscript.

2. Please use only one term (ET or LE) consistently throughout the manuscript. It would be easier for people to read this manuscript.

$\rightarrow$ We have accepted your suggestion and made changes throughout text, figures and tables.

3. In the section 2.1, please list the most important equations in the BESS model for ET calculations. And please list the full name of the variables before using the abbreviations (e.g. aVIS, Vcmax, etc.)

$\rightarrow$ We appreciate your suggestion. The most important equations in the BESS model for ET calculations are now listed in Appendix 1 in the revised version (L570). Full names of LAI, $\alpha$ VIS and $\alpha$ NIR were listed in L90. Full name of Vcmax25 was shown in L120.

4. Ln. 205, please show the equation for clear demonstration.

$\rightarrow$ We have followed your suggestion. We have added a Table 1 "Linear equations for LAI (y) as a function of VI (x) for corn, soybean, and the combination of corn and soybean".

[Table 1]

5. Ln. 254, Cl could not be found in Eq. 6 or 7 . Please check the manuscript clearly to correct this kind of errors.

$\rightarrow$ Thanks for the suggestion. We have deleted this sentence. $\mathrm{Cl}$ is not used. 
6. Fig. 6 , is the irrigation measured in the field?

$\rightarrow$ Yes. The irrigation data at US-Ne1 and US-Ne2 are provided by FLUXNET2015 database.

7. In Fig. 8 and 9, it would be good to point out flux tower sites.

$\rightarrow$ We have followed your suggestion by adding flux tower marks in all maps.

8. I think Fig. 7 could be put in the supplementary materials, since Fig. 6 already showed good performance of BESS-STAIR ET.

$\rightarrow$ We agree that key information have already been shown in Fig. 6 so we have removed this figure.

9. Ln.346-347, the authors said "measured daily LE do not show strong and fast response to precipitation and/or irrigation", however, in Fig. 10, averaged ET showed significant correlations with precipitation. How did the author interpret this?

$\rightarrow$ We appreciate this important point. In most areas in the U.S. Corn Belt, atmospheric water demand dominates ET over soil water supply. In fact, the original Fig. 10 was special because that area-month has the highest correlation between ET and precipitation, thus that figure was not representative and misleading. We have replaced it by another figure:

[Figure 10]

Figure 10. Peak growing season (June, July and August) BESS-STAIR ET/PET at Bondville $\left(39.95^{\circ} \mathrm{N}-40.05^{\circ} \mathrm{N}, 88.25^{\circ} \mathrm{W}-88.35^{\circ} \mathrm{W}\right)$ from 2001 throughout 2017 , along with two scatter plots between peak growing season precipitation and ET/PET and peak growing season VPD and ET/PET over the 17 years. Precipitation and VPD data are from Daily Surface Weather Data (Daymet) at Illinois Bondville, where VPD is derived using maximum air temperature and water vapor pressure. Circles indicate flux towers in this region. Accordingly, we have rewritten the paragraph (L398): "BESS-

Printer-friendly version

Discussion paper 
STAIR is also able to produce long-term ET/PET estimation as an indicator of drought. Figure 10 shows an example time series of peak growing season ET/PET at Bondville from 2001 through 2017. Overall substantial interannual variability is shown, with regional average ET/PET values ranging from the 0.76 in an extremely dry year 2012 to 0.91 in an extremely wet year 2015. A positive linear relationship $(r=0.42, p<0.1)$ is observed between BESS-STAIR ET/PET and precipitation, and a negative linear relationship $(r=-0.58, p<0.05)$ is observed between BESS-STAIR ET/PET and VPD. The relative stronger relationship between ET/PET and VPD than that between ET/PET and precipitation indicates atmospheric water demand is likely to contribute more to drought than soil water supply in this area."

Interactive comment on Hydrol. Earth Syst. Sci. Discuss., https://doi.org/10.5194/hess-2019376, 2019. 
HESSD

2001

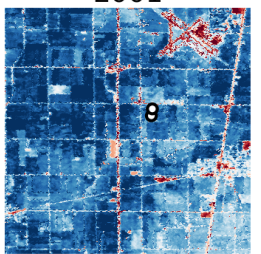
2006

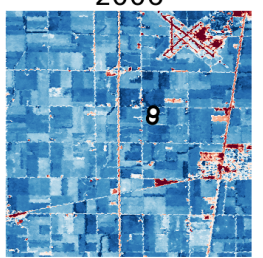
2011

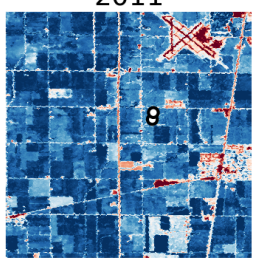
2016

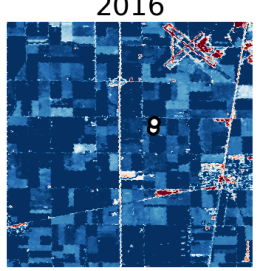

2003

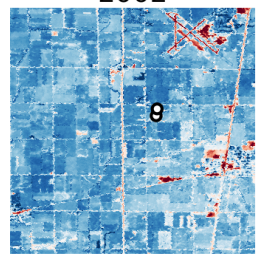
2007

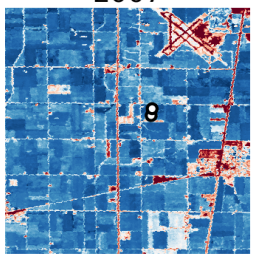
2012

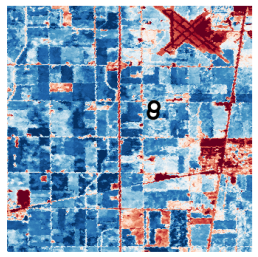
2017

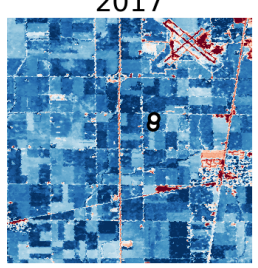
2008

2013
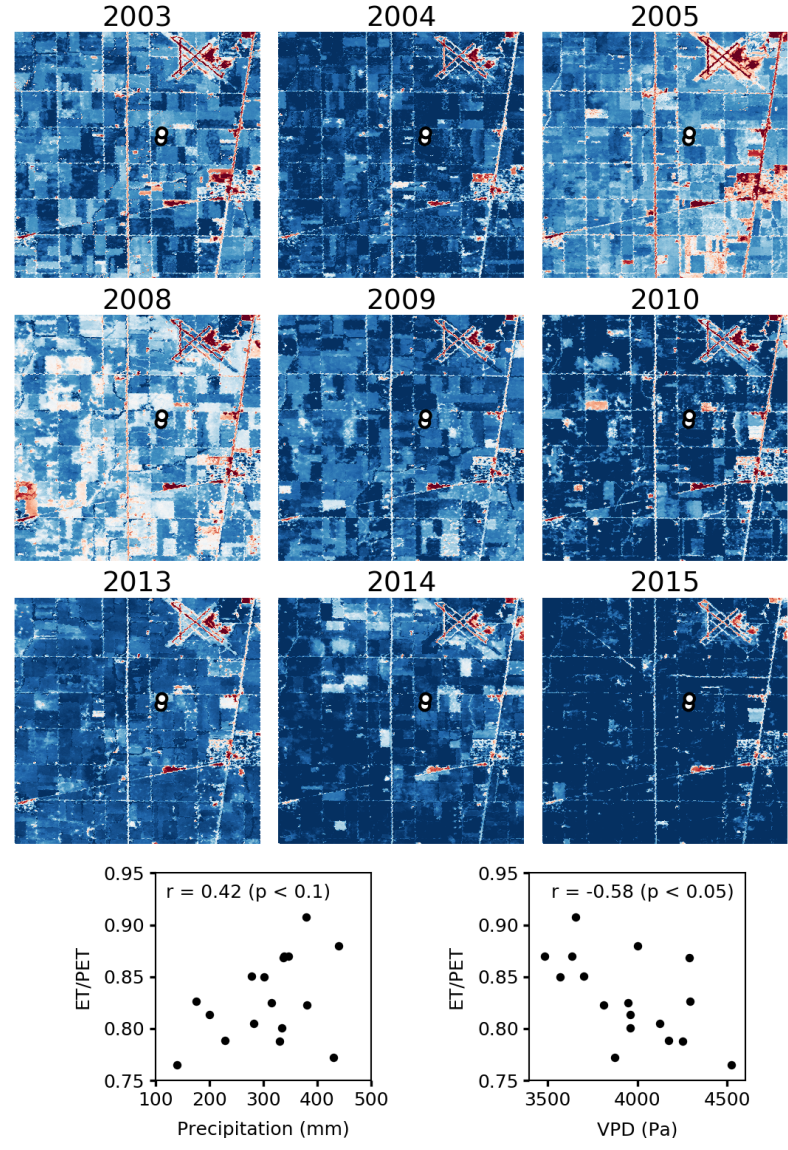

0.90

0.85

0.80

0.75

0.70

0.65

0.60

0.55

0.50

Fig. 1. Figure 10

Interactive

comment

Printer-friendly version

Discussion paper

(c) (1) 


\begin{tabular}{cccc}
\hline VI & Corn & Soybean & Combination \\
\hline WDRVI & $\mathrm{y}=6.288 \mathrm{x}+4.631$ & $\mathrm{y}=4.584 \mathrm{x}+3.432$ & $\mathrm{y}=5.745 \mathrm{x}+4.288$ \\
GWDRVI & $\mathrm{y}=8.964 \mathrm{x}+5.875$ & $\mathrm{y}=6.384 \mathrm{x}+4.275$ & $\mathrm{y}=8.110 \mathrm{x}+5.395$ \\
EVI & $\mathrm{y}=10.569 \mathrm{x}-2.165$ & $\mathrm{y}=8.116 \mathrm{x}-1.936$ & $\mathrm{y}=9.665 \mathrm{x}-1.993$ \\
LSWI & $\mathrm{y}=9.156 \mathrm{x}+1.070$ & $\mathrm{y}=7.553 \mathrm{x}+0.888$ & $\mathrm{y}=8.944 \mathrm{x}+0.982$
\end{tabular}

Fig. 2. Table 1 